\title{
Renal protective effects of vicenin- 2 and scolymoside in a mouse model of sepsis
}

\author{
Bong-Seon Lee ${ }^{1 \dagger}$, Sumin Yang ${ }^{1 \dagger}$, Changhun Lee ${ }^{1}$, Sae-Kwang Ku ${ }^{2 *}$, Jong-Sup Bae ${ }^{\oplus 1^{*}}$ \\ ${ }^{1}$ College of Pharmacy, CMRI, Research Institute of Pharmaceutical Sciences, BK21 \\ Plus KNU Multi-Omics based Creative Drug Research Team, Kyungpook National \\ University, Daegu, Republic of Korea, ${ }^{2}$ Department of Anatomy and Histology, College \\ of Korean Medicine, Daegu Haany University, Gyeongsan, Republic of Korea
}

\begin{abstract}
This study was initiated to determine whether 2 structurally related flavonoids found in Cyclopia subternata - vicenin-2 (VCN) and scolymoside (SCL) — could modulate renal functional damage in a mouse model of sepsis, and to elucidate the relevant underlying mechanisms. The potential of VCN and SCL treatment to reduce renal damage induced by cecal ligation and puncture (CLP) surgery in mice was measured via assessment of serum creatinine, blood urea nitrogen (BUN), lipid peroxidation, total glutathione, glutathione peroxidase activity, catalase activity, and superoxide dismutase activity. Treatment with either VCN or SCL resulted in elevated plasma levels of BUN and creatinine, and of protein in the urine of mice with CLP-induced renal damage. Moreover, both VCN and SCL inhibited nuclear factor $\kappa \mathrm{B}$ activation and reduced the induction of nitric oxide synthase and excessive production of nitric acid. VCN and SCL treatment also reduced the plasma levels of interleukin-6, and tumor necrosis factor- $\alpha$, reduced lethality due to CLP-induced sepsis, increased lipid peroxidation, and markedly enhanced the antioxidant defense system by restoring the levels of superoxide dismutase, glutathione peroxidase, and catalase in kidney tissues. The present results suggest that VCN and SCL protect mice from sepsis-triggered renal injury.
\end{abstract}

Keywords: Vicenin-2. Scolymoside. Sepsis, Antioxidant, Renal injury, Renal toxicity.

\section{INTRODUCTION}

Sepsis is a serious infection that causes severe inflammatory responses and is associated with a high level of mortality despite recent advances in critical care (Russell, 2006). Cytokine activation is part of the host defense system against infection, but the excessive production of cytokines can cause extensive damage and multiple organ failure (MOF) (Chaudhry et al., 2013). Sepsis induces the activation of inducible nitric oxide synthase (iNOS) and upregulates the production of nitric oxide (NO) and reactive oxygen species

\footnotetext{
*Correspondence: S.-K. Ku, Department of Histology and Anatomy, College of Korean Medicine, Daegu Haany University, 1 Haanydaero, Gyeongsan-si 38610, Republic of Korea. Phone: 82-53-819-1549; Fax, 82-53-819-1860. E-mail: gucci200@hanmail.net. J.-S. Bae, College of Pharmacy, Kyungpook National University, 80 Daehak-ro, Buk-gu, Daegu 41566, Republic of Korea. Phone: 82-53-950-8570; Fax, 82-53-950-8557. E-mail,baejs@knu.ac.kr
}

(ROS), leading to cellular toxicity (Parratt, 1998; Symeonides and Balk, 1999). Sepsis-induced MOF may be reduced by inhibiting inflammatory cytokine production and iNOS activity (Draisma et al., 2010; Parratt, 1998; Symeonides, Balk, 1999). In addition, the overproduction of ROS can cause oxidative stress, as indicated by a decrease in the endogenous antioxidant defense system and lipid peroxidation. Therefore, new drug candidates that inhibit the production of ROS and inflammatory cytokines may help in the management of severe sepsis or septic shock (Cadenas, Cadenas, 2002; Vincent et al., 2000).

Tea and herbal infusions are natural beverages containing compounds that are of particular interest to the health sciences owing to their potential in vivo biological properties (Prior, Cao, 1999; Warren, 1999). Health-promoting properties such as antioxidant, anti-inflammatory, and memory-enhancing activities 
have been documented for active compounds found in Cyclopia subternata, Peperomia blanda, Ocimum sanctum, Perilla frutescens, Urtica circularis, and Potentilla discolor (Islam et al., 2014; Joubert et al., 2011; Leiro et al., 2003; Pardo Andreu et al., 2010; Sanchez et al., 2000). C. subternata is known to contain abundant flavonoids, particularly vicenin-2 (VCN) and scolymoside (SCL) (Kazuno et al., 2005). Furthermore, previous reports have shown that VCN exerts antidiabetic, anti-glycation, and anti-inflammatory activities (Islam et al., 2014; Marrassini et al., 2011). However, the beneficial effects of VCN and SCL on sepsis-induced renal damage have not yet been studied. Therefore, in this study, we investigated the renal protective effects of VCN and SCL in an animal model of sepsis.

\section{MATERIAL AND METHODS}

\section{Animals and sepsis mouse model}

Before cecal ligation and puncture (CLP) surgery, male C57BL/6 mice (average weight 27 g; Sungnam, Republic of Korea) were anesthetized using Rompum (xylazine, $10 \mathrm{mg} / \mathrm{kg}$ ) and Zoletil $(30 \mathrm{mg} / \mathrm{kg}$ ). The CLPinduced sepsis mouse model was developed as previously described (Bae et al., 2014; Wang et al., 2004), and sham-operated animals were used as controls. Animals were randomly divided into the following groups $(\mathrm{n}=10$ each): sham-operated control; VCN or SCL only (1.2 mg/ kg body weight; Sigma-Aldrich, St. Louis, MO, USA), administrated in $0.5 \%$ dimethyl sulfoxide (DMSO); CLP surgery only; and CLP + VCN or SCL $(0.3,0.6$, or 1.2 $\mathrm{mg} / \mathrm{kg}$ body weight). VCN and SCL were intravenously injected $12 \mathrm{~h}$ after CLP and again $50 \mathrm{~h}$ after CLP. Blood and organ samples were collected 4 days after VCN or SCL injection for functional assays. This protocol was approved by the Animal Care Committee at Kyungpook National University prior to conducting the study (IRB No. KNU 2017-102).

\section{Cell culture}

Primary human umbilical vein endothelial cells (HUVECs) were purchased from Cambrex Bio Science (Charles City, IA, USA), maintained as previously described (Jung et al., 2016; Kim, Bae, 2016), and used after three to five passages.

\section{Sample preparation and evaluation of nephrotoxicity and lactate dehydrogenase (LDH)}

Four days after VCN or SCL injection, blood, urine, and kidney samples were collected and prepared as previously described (Lee et al., 2017). Renal dysfunctional markers, such as BUN and creatinine, and a tissue injury marker (LDH) were measured as previously described (Lee et al., 2017).

\section{Plasma nitrite/nitrate determination}

Levels of nitrite and nitrate in the plasma were determined using Griess reagents and vanadium solution (VCl3), as previously described (Lee et al., 2017; Miranda, Espey, Wink, 2001). Briefly, each sample (100 $\mu \mathrm{L})$ was mixed with $\mathrm{VCl} 3(100 \mu \mathrm{L})$ and incubated with Griess reagents. After $30 \mathrm{~min}$, the optical density was measured at $540 \mathrm{~nm}(\mathrm{OD} 540 \mathrm{~nm})$ and a change in color was monitored. Sodium nitrite standards were used to prepare a standard curve to measure the final nitrite/ nitrate concentrations.

\section{Determination of tumor necrosis factor- alpha (TNF- $\alpha$ ), interleukin (IL)-6, and renal myeloperoxidase (MPO) activity via enzyme- linked immunosorbent assays (ELISA)}

Levels of IL-6, TNF- $\alpha$ (R\&D Systems, Minneapolis, MN, USA), and MPO (Abcam, Cambridge, UK) in plasma were determined using commercially available ELISA kits.

\section{Evaluation of oxidative stress markers}

Lipid peroxidation, malondialdehyde (MDA), total glutathione (GSH), superoxide dismutase (SOD), glutathione peroxidase (GSH-Px), and catalase activities (CAT) were measured as described previously (Beutler, Duron, Kelly, 1963; Lee et al., 2017).

\section{Western blotting}

Kidney samples were prepared and western blotting using primary antibodies for iNOS, inhibitor of kappa B

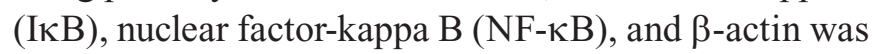
conducted as previously described (Lee et al., 2017). 


\section{Cell viability assay}

Cellular viability was measured via 3-(4,5-dimethylthiazol-2-yl)-2,5-diphenyltetrazoliumbromide (MTT) assay, as previously described (Lee et al., 2017). HUVECs were incubated with VCN or SCL for $48 \mathrm{~h}$.

\section{RESULTS}

\section{VCN and SCL reduced CLP-induced renal tissue injury and plasma nitrite and nitrate production}

CLP surgery increased nephrotoxic markers levels (Table I), such as BUN and creatinine in blood, and protein concentrations in the urine compared to those in the sham-operated group, all of which were reduced by administration of VCN and SCL $(0.3,0.6$, or $1.2 \mathrm{mg} / \mathrm{kg}, 12 \mathrm{~h}$ and $50 \mathrm{~h}$ after CLP). Levels of LDH, a marker of general tissue injury, were also reduced by VCN and SCL treatment in CLP-operated mice (Table I). In addition, the effects of VCN and SCL treatment on the inflammatory response in kidney tissue were investigated in vivo by measuring plasma nitrite and nitrate levels (stable end products of NO). NO production in CLP-operated mice was significantly increased (7.3-fold) compared to that in the control group (Table II), and was reduced by treatment with VCN or SCL (Table II).

TABLE I - Effects of VCN or SCL treatment on plasma levels of BUN and creatinine and urine level of protein in CLP-operated micea

\section{BUN (mg/dL) Creatinine (mg/dL) Urine protein (mg/12 hour) LDH (U/dL)}

\begin{tabular}{|c|c|c|c|c|}
\hline Sham & $14.6 \pm 0.6$ & $0.118 \pm 0.02$ & $2.3 \pm 0.21$ & $256 \pm 15.27$ \\
\hline $\begin{array}{l}\text { VCN } \\
(1.2 \mathrm{mg} / \mathrm{kg})\end{array}$ & $14.9 \pm 0.5$ & $0.125 \pm 0.01$ & $2.1 \pm 0.25$ & $265 \pm 14.9$ \\
\hline $\begin{array}{l}\mathrm{SCL} \\
(1.2 \mathrm{mg} / \mathrm{kg})\end{array}$ & $15.2 \pm 0.4$ & $0.123 \pm 0.02$ & $2.2 \pm 0.27$ & $259 \pm 20.3$ \\
\hline CLP & $78.9 \pm 4.3$ & $0.425 \pm 0.03$ & $13.9 \pm 0.57$ & $3570 \pm 150.8$ \\
\hline $\begin{array}{l}\text { CLP + VCN } \\
(0.3 \mathrm{mg} / \mathrm{kg})\end{array}$ & $77.5 \pm 3.5$ & $0.431 \pm 0.02$ & $13.6 \pm 0.42$ & $3380 \pm 210.4$ \\
\hline $\begin{array}{l}\text { CLP + VCN } \\
(0.6 \mathrm{mg} / \mathrm{kg})\end{array}$ & $55.3 \pm 4.7^{*}$ & $0.289 \pm 0.02 *$ & $7.2 \pm 0.52 *$ & $2250 \pm 150.5^{*}$ \\
\hline $\begin{array}{l}\text { CLP + VCN } \\
(1.2 \mathrm{mg} / \mathrm{kg})\end{array}$ & $30.2 \pm 2.5^{*}$ & $0.215 \pm 0.02 *$ & $3.9 \pm 0.23^{*}$ & $1280 \pm 125.3^{*}$ \\
\hline $\begin{array}{l}\text { CLP + SCL } \\
(0.3 \mathrm{mg} / \mathrm{kg})\end{array}$ & $75.6 \pm 4.3$ & $0.422 \pm 0.03$ & $13.2 \pm 0.31$ & $3480 \pm 250.9$ \\
\hline $\begin{array}{l}\text { CLP + SCL } \\
(0.6 \mathrm{mg} / \mathrm{kg})\end{array}$ & $59.2 \pm 3.9^{*}$ & $0.275 \pm 0.03^{*}$ & $6.9 \pm 0.47^{*}$ & $2580 \pm 120.4 *$ \\
\hline $\begin{array}{l}\text { CLP + SCL } \\
(1.2 \mathrm{mg} / \mathrm{kg})\end{array}$ & $32.5 \pm 3.1^{*}$ & $0.202 \pm 0.02 *$ & $3.5 \pm 0.31^{*}$ & $1350 \pm 102.2^{*}$ \\
\hline
\end{tabular}

${ }^{a}$ Each value represents the mean $\pm \mathrm{SD}(\mathrm{n}=10)$.

Sham, sham-operated mice; VCN or SCL, mice treated with VCN or SCL (1.2 mg/kg body weight) at 12 and $50 \mathrm{~h}$; CLP, CLPoperated mice; VCN or SCL + CLP, mice treated with PEL at 12 and $50 \mathrm{~h}$ after CLP surgery.

$* p<0.05$ as compared to CLP. 
TABLE II - Effects of VCN or SCL treatment on NO, TNF- , IL-6 levels and renal MPO activity in CLP-operated micea

\begin{tabular}{|c|c|c|c|c|}
\hline & NO (mM) & TNF-a (pg/mL) & IL-6 (pg/mL) & MPO (U/g tissue) \\
\hline Sham & $30.8 \pm 2.5$ & $111.3 \pm 8.6$ & $0.69 \pm 0.06$ & $0.59 \pm 0.04$ \\
\hline $\begin{array}{l}\mathrm{VCN} \\
(1.2 \mathrm{mg} / \mathrm{kg})\end{array}$ & $31.5 \pm 3.1$ & $121.5 \pm 8.9$ & $0.72 \pm 0.05$ & $0.58 \pm 0.05$ \\
\hline $\begin{array}{l}\mathrm{SCL} \\
(1.2 \mathrm{mg} / \mathrm{kg})\end{array}$ & $30.9 \pm 2.8$ & $123.8 \pm 10.2$ & $0.71 \pm 0.04$ & $0.52 \pm 0.06$ \\
\hline CLP & $218.9 \pm 15.3$ & $528.4 \pm 41.9$ & $75.42 \pm 6.15$ & $3.42 \pm 0.32$ \\
\hline $\begin{array}{l}\text { CLP + VCN } \\
(0.3 \mathrm{mg} / \mathrm{kg})\end{array}$ & $220.2 \pm 18.7$ & $535.6 \pm 35.3$ & $79.71 \pm 5.83$ & $3.59 \pm 0.41$ \\
\hline $\begin{array}{l}\text { CLP + VCN } \\
(0.6 \mathrm{mg} / \mathrm{kg})\end{array}$ & $156.4 \pm 12.5^{*}$ & $301.7 \pm 21.3^{*}$ & $43.25 \pm 4.11^{*}$ & $2.37 \pm 0.25^{*}$ \\
\hline $\begin{array}{l}\text { CLP + VCN } \\
(1.2 \mathrm{mg} / \mathrm{kg})\end{array}$ & $85.8 \pm 7.3^{*}$ & $185.9 \pm 14.7^{*}$ & $22.64 \pm 2.32^{*}$ & $1.19 \pm 0.17^{*}$ \\
\hline $\begin{array}{l}\text { CLP + SCL } \\
(0.3 \mathrm{mg} / \mathrm{kg})\end{array}$ & $215.4 \pm 12.9$ & $531.5 \pm 31.4$ & $78.52 \pm 6.12$ & $3.47 \pm 0.39$ \\
\hline $\begin{array}{l}\text { CLP + SCL } \\
(0.6 \mathrm{mg} / \mathrm{kg})\end{array}$ & $170.3 \pm 13.1^{*}$ & $310.4 \pm 25.7^{*}$ & $45.19 \pm 3.15^{*}$ & $2.41 \pm 0.31^{*}$ \\
\hline $\begin{array}{l}\text { CLP + SCL } \\
(1.2 \mathrm{mg} / \mathrm{kg})\end{array}$ & $82.9 \pm 6.2^{*}$ & $175.4 \pm 11.8^{*}$ & $23.57 \pm 2.18^{*}$ & $1.25 \pm 0.11^{*}$ \\
\hline
\end{tabular}

${ }^{a}$ Each value represents the mean $\pm \mathrm{SD}(\mathrm{n}=10)$.

Sham, sham-operated mice; VCN or SCL, mice treated with VCN or SCL (1.2 mg/kg body weight) at 12 and $50 \mathrm{~h}$; CLP, CLPoperated mice; VCN or SCL + CLP, mice treated with PEL at 12 and $50 \mathrm{~h}$ after CLP surgery.

$* p<0.05$ as compared to CLP.

\section{VCN and SCL inhibited TNF- $\alpha$, IL-6, MPO, and MDA levels induced by CLP}

Next, we determined the effects of VCN and SCL on inflammatory markers such as TNF- $\alpha$ and IL-6. Treatment with VCN and SCL inhibited CLP-induced production of TNF- $\alpha$ and IL- 6 in plasma (Table II). Next, we tested the effects of VCN and SCL on the infiltration of neutrophils by measuring MPO levels (an indicator of renal infiltration by neutrophils) after CLP surgery. We identified a marked increase in MPO levels after CLP surgery (Table II), which was associated with nephritis. Post-surgical treatment with VCN or SCL resulted in significantly lower MPO concentrations in renal tissues than in CLP-operated mice. We also determined the effects of VCN and SCL on MDA, an indicator of lipid peroxidation levels. Increased MDA levels induced by CLP were reduced by treatment with VCN or SCL (Table III). 
Renal protective effects of vicenin-2 and scolymoside in a mouse model of sepsis

TABLE III - Effects of VCN or SCL treatment on MDA level and the activities of renal antioxidant enzymes in CLP-operated micea

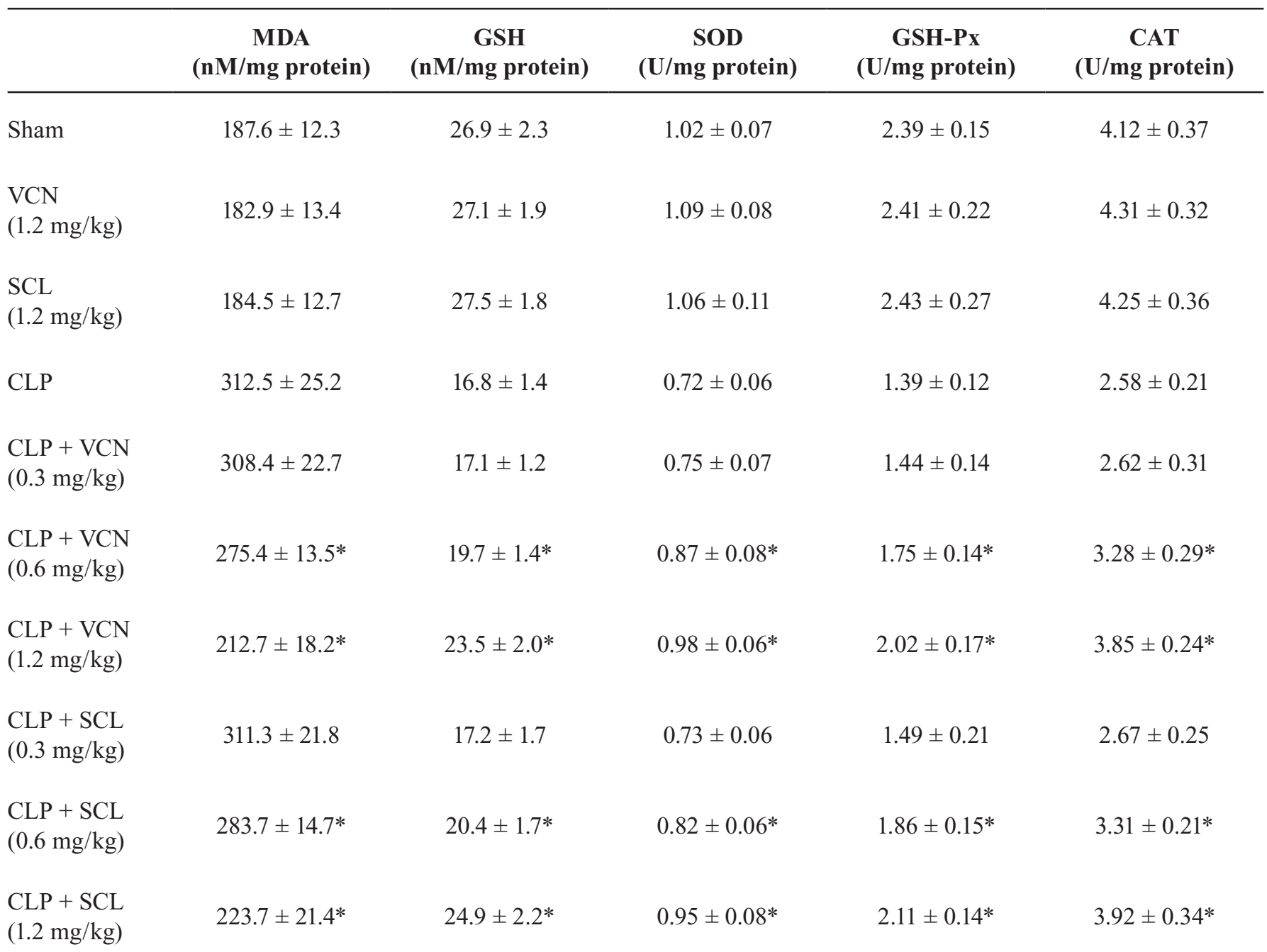

${ }^{a}$ Each value represents the mean $\pm \mathrm{SD}(\mathrm{n}=10)$.

Sham, sham-operated mice; VCN or SCL, mice treated with VCN or SCL (1.2 mg/kg body weight) at 12 and $50 \mathrm{~h}$; CLP, CLPoperated mice; VCN or SCL + CLP, mice treated with PEL at 12 and $50 \mathrm{~h}$ after CLP surgery.

$* p<0.05$ as compared to CLP.

\section{VCN and SCL increased total GSH and antioxidant enzyme activity in the kidney tissues}

We determined whether VCN and SCL could control CLP-induced oxidative stress by measuring antioxidant GSH levels and activities of the oxidative stress-associated enzymes SOD, GSH-Px, and CAT. Total GSH levels and the activities of SOD, GSH-Px, and CAT were similar to those in the VCN only, SCL only, and sham-operated groups. In contrast, the total GSH levels and renal activities of all three enzymes were reduced in CLP-operated mice and were increased by treatment with VCN or SCL (Table III).

\section{VCN and SCL reduced renal proteins and iNOS levels, and inhibited NF- $\kappa$ B activity}

We investigated the levels of iNOS, I $\mathrm{B}$, and NF$\kappa \mathrm{B}$ to define the underlying renal protective effects of VCN and SCL. Elevated protein levels of iNOS by CLP were dramatically reduced by treatment with $\mathrm{VCN}$ or SCL (Figure 1). Next, we determined the effects 
of VCN and SCL on I $\mathrm{B}$ degradation by CLP and translocation of NF- $\kappa \mathrm{B}$ in the cell. CLP-induced $\mathrm{I} \kappa \mathrm{B}$ degradation was significantly lowered by treatment with VCN or SCL and decreased levels of NF- $\kappa \mathrm{B}$ p 65 in the cytosol were reversed by treatment with VCN or SCL (Figure 1A). In addition, the cellular toxicity of VCN and SCL was determined via MTT assay, showing that neither VCN nor SCL affected cellular viability when administered at concentrations up to $100 \mu \mathrm{M}$ (Figure 1B).
A

\section{$\mathrm{VCN}$ or $\mathrm{SCL}$ [1.2 $\mathrm{mg} / \mathrm{kg}$ ]}
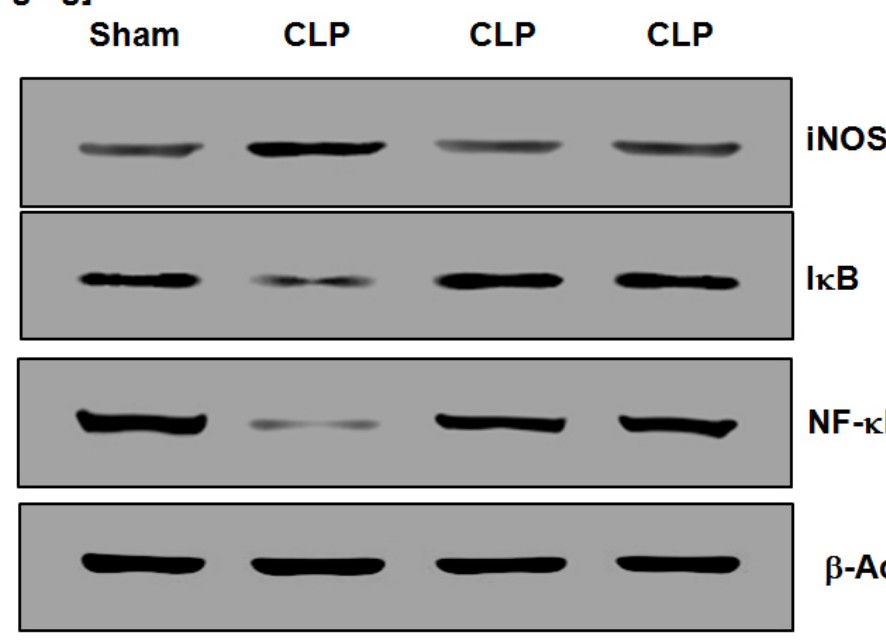

B

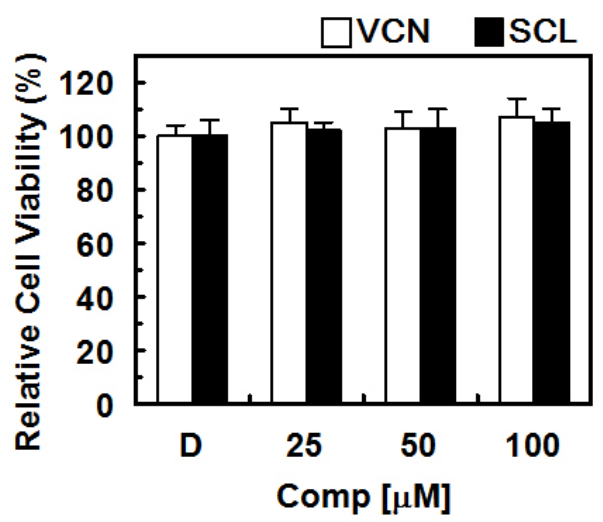

FIGURE 1 - Effects of vicenin-2 (VCN) and scolymoside (SCL) treatment on renal inducible nitric oxide synthase (iNOS),

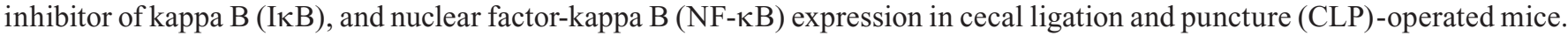
(A) Sham-operated mice; CLP-operated mice; mice treated with VCN or SCL (1.2 mg/kg body weight) $12 \mathrm{~h}$ and $50 \mathrm{~h}$ after CLP

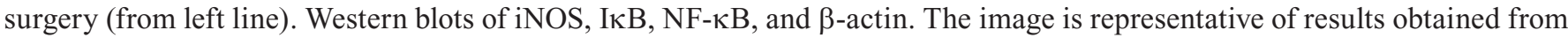
three different experiments. (B) The effects of VCN and SCL on cellular viability were measured via MTT assay. D $=0.2 \%$ dimethyl sulfoxide (DMSO), used as the vehicle control. The results are shown as means \pm SD from three separate experiments on different days performed in triplicate.

\section{VCN and SCL reduced CLP-induced septic lethality}

To confirm the renal protective effects of $\mathrm{VCN}$ and SCL, we tested their effects on CLP-induced lethality. Data showed that injection with VCN or SCL $(1.2 \mathrm{mg} / \mathrm{kg}, 12 \mathrm{~h}$ and $50 \mathrm{~h}$ after CLP) increased the survival rate $(50 \%)$ of CLP-operated mice $(p<0.0001$, Figure 2). 


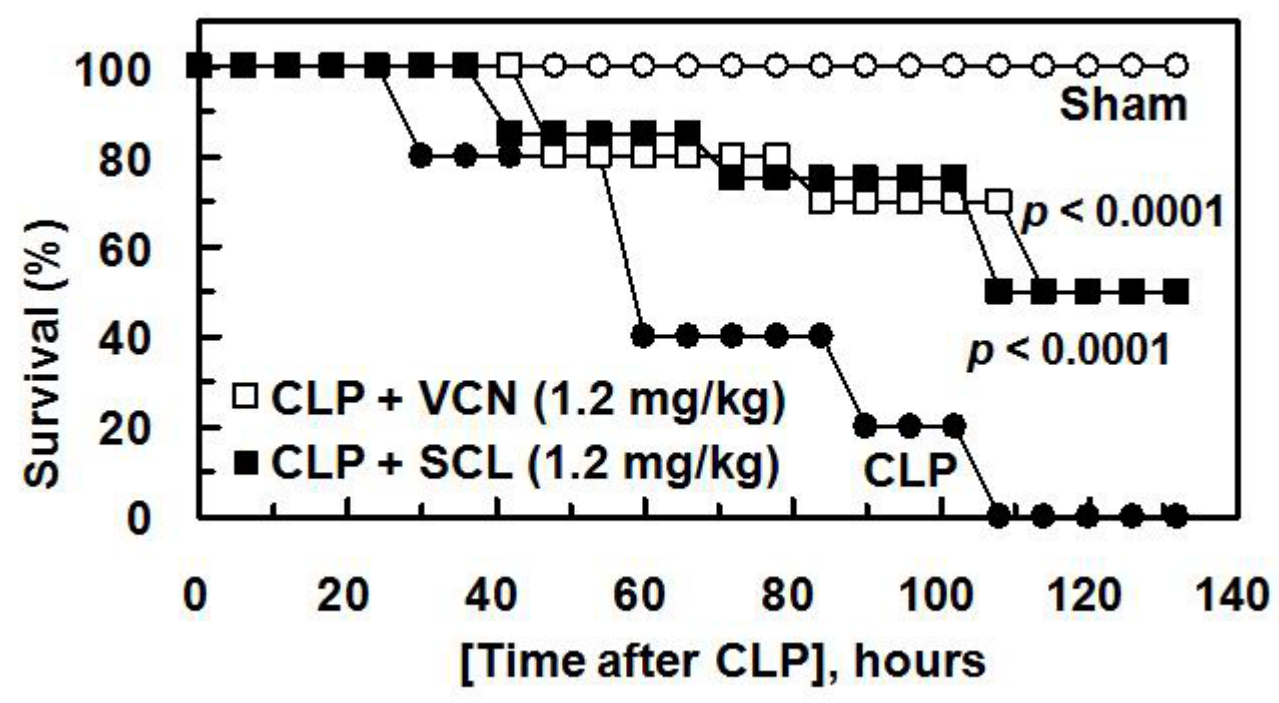

FIGURE 2 - Effects of VCN and SCL on CLP-induced septic lethality. Male C57BL/6 mice $(\mathrm{n}=20)$ were administered VCN or $\mathrm{SCL}$ at $1.2 \mathrm{mg} / \mathrm{kg}$ (intravenous, i.v.) $12 \mathrm{~h}$ and $50 \mathrm{~h}$ after CLP. Animal survival was monitored every $12 \mathrm{~h}$ for $132 \mathrm{~h}$ after CLP. Control CLP-operated mice ( ) and sham-operated mice ( ) were administered sterile saline ( $\mathrm{n}=20)$. Kaplan-Meier survival analysis was used to determine the overall survival rates versus treated CLP-operated mice.

\section{DISCUSSION}

In this study, we report that: (1) the expression of plasma BUN and creatinine and urine protein levels were increased by CLP, but decreased by VCN and SCL treatment; (2) CLP increased renal tissue injury inflammatory protein markers, and treatment with VCN and SCL reduced these levels; (3) CLPoperated mice showed increased NO production in the blood and iNOS expression, which was significantly attenuated by treatment with VCN or SCL; and (4) VCN and SCL increased GSH and antioxidant enzyme activity. Therefore, the renal protective effects of VCN and SCL were mediated by reducing NO production and inflammatory protein levels, and increasing antioxidant enzymes.

It is well known that levels of TNF- $\alpha$, IL-6, and $\mathrm{NF}-\kappa \mathrm{B}$ are increased under severe inflammatory conditions (Chaudhry et al., 2013; Stearns-Kurosawa et al., 2011). Based on the current findings that VCN and SCL inhibited the upregulation of TNF- $\alpha$ and IL-6, and NF- $\kappa B$ by CLP, we concluded that the renal protective effects of VCN and SCL were mediated by suppressing inflammatory gene expression. When cells are activated by inflammatory mediators, NF- $\kappa \mathrm{B}$ dissociates from $\mathrm{I} \kappa \mathrm{B}$ and translocates to the nucleus (Oeckinghaus, Ghosh, 2009). NF- $\kappa \mathrm{B}$ is a potential primary target for inflammatory diseases, as the renal protective mechanisms of VCN and SCL were mediated by inhibiting the degradation of I $\mathrm{B}$ and the CLPmediated activation of NF- $\kappa \mathrm{B}$.

Genes encoding three antioxidant enzymes (SOD, CAT, and GSH-Px) are regarded as the primary oxidative defense genes (Birben et al., 2012). CLP surgery lowered the expression levels of SOD, CAT, and GSH-Px, but these were significantly increased by VCN and SCL treatment, indicating that these exert cytoprotective effects on CLP-induced oxidative damage in renal tissues. CLP also increased renal MDA concentrations, a major lipid peroxidation product and oxidative stress marker (Qiao et al., 2011; Xiao et al., 2012; Zhang et al., 2011), and these were reduced by VCN and SCL administration. Therefore, VCN and SCL protected against CLP-induced oxidative stress and injury through suppression of lipid peroxidation and activation of antioxidant enzymes.

Intravenously injected VCN or SCL $(1.2 \mathrm{mg} /$ $\mathrm{kg}$ ) showed renal protective functions against CLPinduced responses. Considering that the average weight of mice used in this study was $27 \mathrm{~g}$ and the 
average weight of an adult human is $70 \mathrm{~kg}$, we would require $84 \mathrm{mg}$ of $\mathrm{VCN}$ or $\mathrm{SCL}$ to achieve renal protective effects if the compound is administrated intravenously in humans. However, if the compounds are ingested through herbal tea, an amount greater than this would be needed for the following reasons: 1) large differences exist between intravenous injection and the oral route; 2 ) after ingesting the tea, several pharmacological processes are required for the compound (VCN or SCL) to reach the bloodstream, such as absorption, distribution, metabolism, and excretion (ADME); and 3) the entire content of the compound in the herbal tea is not absorbed. In order for a consumed compound to be effectively utilized by the body's vascular system, these four processes (ADME), which represent the distribution of a pharmaceutical compound within an organism, must be optimized. These properties influence the compound levels and the kinetics of exposure of the tissues to the compound; hence, these criteria influence the performance and pharmacological activity of the compound.

Collectively, our data have demonstrated the renal protective effects of VCN and SCL against sepsis. The beneficial activities of VCN and SCL were accompanied by lower levels of TNF- $\alpha$, IL-6, iNOS, and NO, via inhibition of the NF- $\kappa \mathrm{B}$ signaling pathway, which is associated with increased antioxidant defenses and decreased lipid peroxidation in vivo. Therefore, VCN and SCL show potential for therapeutic use in the treatment of renal inflammatory diseases.

\section{ADDITIONAL INFORMATION}

Competing financial interests: the authors declare no competing financial interests.

\section{ACKNOWLEDGEMENTS}

This research was supported by the Bio \& Medical Technology Development Program of the National Research Foundation (NRF) funded by the Ministry of Science \& ICT (2017M3A9G8083382, 2018R1A5A2025272).

\section{REFERENCES}

Bae JS, Lee W, Nam JO, Kim JE, Kim SW, Kim IS. Transforming growth factor beta-induced protein promotes severe vascular inflammatory responses. Am J Respir Crit Care Med. 2014;189(7):779-786.

Beutler E, Duron O, Kelly BM. Improved method for the determination of blood glutathione. J Lab Clin Med. 1963;61:882-888.

Birben E, Sahiner UM, Sackesen C, Erzurum S, Kalayci O. Oxidative stress and antioxidant defense. World Allergy Organ J. 2012;5(1):9-19.

Cadenas S, Cadenas AM. Fighting the stranger-antioxidant protection against endotoxin toxicity. Toxicology. 2002;180(1):45-63.

Chaudhry H, Zhou J, Zhong Y, Ali MM, McGuire F, Nagarkatti PS, et al. Role of cytokines as a double-edged sword in sepsis. In vivo. 2013;27(6):669-684.

Draisma A, Dorresteijn MJ, Bouw MP, van der Hoeven JG, Pickkers P. The role of cytokines and inducible nitric oxide synthase in endotoxemia-induced endothelial dysfunction. J Cardiovasc Pharmacol. 2010;55(6):595-600.

Islam MN, Ishita IJ, Jung HA, Choi JS. Vicenin 2 isolated from Artemisia capillaris exhibited potent anti-glycation properties. Food Chem Toxicol. 2014;69:55-62.

Joubert E, Joubert ME, Bester C, De Beer D, De Lange JH. Honeybush (Cyclopia spp.): From local cottage industry to global markets - The catalytic and supporting role of research. S Afr J Bot. 2011;77(4):889-907.

Jung B, Kang H, Lee W, Noh HJ, Kim YS, Han MS, et al. Anti-septic effects of dabrafenib on HMGB1-mediated inflammatory responses. BMB Rep. 2016;49(4):214-219.

Kazuno S, Yanagida M, Shindo N, Murayama K. Mass spectrometric identification and quantification of glycosyl flavonoids, including dihydrochalcones with neutral loss scan mode. Anal Biochem. 2005;347(2):182-192.

Kim J, Bae JS. ROS homeostasis and metabolism: a critical liaison for cancer therapy. Exp Mol Med. 2016;48(11):e269.

Lee W, Lee Y, Jeong GS, Ku SK, Bae JS. Cudratricusxanthone A attenuates renal injury in septic mice. Food Chem Toxicol. 2017;106(Pt A):404-410.

Leiro JM, Alvarez E, Arranz JA, Siso IG, Orallo F. In vitro effects of mangiferin on superoxide concentrations and expression of the inducible nitric oxide synthase, tumour necrosis factor-alpha and transforming growth factor-beta genes. Biochem Pharmacol. 2003;65(8):1361-1371. 
Renal protective effects of vicenin-2 and scolymoside in a mouse model of sepsis

Marrassini C, Davicino R, Acevedo C, Anesini C, Gorzalczany S, Ferraro G. Vicenin-2, a potential antiinflammatory constituent of urtica circularis. J Nat Prod. 2011;74(6):1503-1507.

Miranda KM, Espey MG, Wink DA. A rapid, simple spectrophotometric method for simultaneous detection of nitrate and nitrite. Nitric Oxide. 2001;5(1):62-71.

Oeckinghaus A, Ghosh S. The NF-kappaB family of transcription factors and its regulation. Cold Spring Harb Perspect Biol. 2009;1(4):a000034.

Pardo Andreu GL, Maurmann N, Reolon GK, de Farias CB, Schwartsmann G, Delgado R, et al. Mangiferin, a naturally occurring glucoxilxanthone improves long-term object recognition memory in rats. Eur J Pharmacol. 2010;635(13):124-128.

Parratt JR. Nitric oxide in sepsis and endotoxaemia. J Antimicrob Chemother. 1998;41(Suppl A):31-39.

Prior RL, Cao G. Antioxidant capacity and polyphenolic components of teas: implications for altering in vivo antioxidant status. Proc Soc Exp Biol Med. 1999;220(4):255-261.

Qiao Y, Bai XF, Du YG. Chitosan oligosaccharides protect mice from LPS challenge by attenuation of inflammation and oxidative stress. Int Immunopharmacol. 2011;11(1):121-127.

Russell JA. Management of sepsis. N Engl J Med. 2006;355(16):1699-1713.

Sanchez GM, Re L, Giuliani A, Nunez-Selles AJ, Davison GP, Leon-Fernandez OS. Protective effects of Mangifera indica L. extract, mangiferin and selected antioxidants against TPA- induced biomolecules oxidation and peritoneal macrophage activation in mice. Pharmacol Res. 2000;42(6):565-573.

Stearns-Kurosawa DJ, Osuchowski MF, Valentine C, Kurosawa S, Remick DG. The pathogenesis of sepsis. Annu Rev Pathol. 2011;6:19-48.

Symeonides S, Balk RA. Nitric oxide in the pathogenesis of sepsis. Infect Dis Clin North Am. 1999;13(2):449-463.

Vincent JL, Zhang H, Szabo C, Preiser JC. Effects of nitric oxide in septic shock. Am J Respir Crit Care Med. 2000;161(6):1781-1785.

Wang H, Liao H, Ochani M, Justiniani M, Lin X, Yang L, et al. Cholinergic agonists inhibit HMGB1 release and improve survival in experimental sepsis. Nat Med. 2004;10(11): 1216-1221.

Warren CP. Antioxidant effects of herbs. Lancet. 1999;353(9153):676.

Xiao JH, Xiao DM, Chen DX, Xiao Y, Liang ZQ, Zhong JJ. Polysaccharides from the medicinal mushroom cordyceps taii show antioxidant and immunoenhancing activities in a D-Galactose-induced aging mouse model. Evidence-Based Complementary Alternative Med. 2012;2012:273435.

Zhang J, Yu Y, Zhang Z, Ding Y, Dai X, Li Y. Effect of polysaccharide from cultured Cordyceps sinensis on immune function and anti-oxidation activity of mice exposed to $60 \mathrm{Co}$. Int Immunopharmacol. 2011;11(12):2251-2257.

Received for publication on $06^{\text {th }}$ August 2018 Accepted for publication on $18^{\text {th }}$ December 2018 